\title{
Pervaporation Dehydration of Ethanol with Malic Acid Crosslinked Graphene/Poly(Vinyl Alcohol) Nanocomposite Membranes
}

\author{
Nguyen Huu Hieu ${ }^{1,2, *}$
}

${ }^{1}$ Faculty of Chemical Engineering; ${ }^{2}$ Key Laboratory of Chemical Engineering and Petroleum Processing, Research Institute of Sustainable Energy, Ho Chi Minh City University of Technology, VNU-HCMC, 268 Ly Thuong Kiet Street, District 10, Ho Chi Minh City, Vietnam

\begin{abstract}
Graphene (GE) based poly(vinyl alcohol) (PVA) nanocomposite membranes were prepared by solution blending method. The influence of GE on morphological, structural, and thermal properties of GE/PVA membranes was studied. Then, malic acid (MA) was used as a crosslinker of the nanocomposite membranes. The effect of MA content on the degree of crosslinking, thermal, mechanical properties, and pervaporation (PV) performance of nanocomposite membranes was investigated. The characterizations of GE/PVA and MA crosslinked GE/PVA nanocomposite membranes were performed by X-ray diffraction spectrum, transmission electron microscope, Fourier-transform infrared spectroscopy, and differential scanning calorimetry, and tensile testing. The characterization results indicated that the good compatibility between GE and PVA was obtained with $0.5 \mathrm{wt} \%$ filler content. Thermal stability and mechanical properties of MA crosslinked GE/PVA membranes were enhanced by adding $20 w t \%$ MA with respect to PVA. The best PV performance for dehydration of $50 \mathrm{wt} \%$ ethanol solution was obtained by using the $20 \mathrm{wt} \% \mathrm{MA}$ crosslinked GE/PVA membrane. This membrane showed that the total permeation flux and selectivity are $0.690 \mathrm{~kg} / \mathrm{m}^{2} \mathrm{~h}$ and 23.89 , respectively.
\end{abstract}

Keywords: Graphene, PVA, malic acid, pervaporation, dehydration, ethanol.

\section{INTRODUCTION}

PVis an important membrane process for the separation of azeotropic mixtures, close-boiling systems, isomeric or heat-sensitive compounds. This technique has advantages such as simplicity, no separating agents or chemicals required, save energy and minimal environmental impact. The popular application of $\mathrm{PV}$ process is dehydration of alcohols and other organic solvents. PVA has proved to be an ideal polymer for fabricating membranes used in separation of ethanol-water mixtures because of its polar, hydrophilic, low cost, and good membraneforming properties. However, PVA membranes often perform poorly in PV due to swelling in water and decline of stability at high temperature [1].

In this respect, improvement in the PV performance has been achieved by adding inorganic particles to the polymer matrix to form nanocomposite membranes. Such nanocomposite membranes have both membrane-forming properties of the polymer and physicochemical stability of the inorganic particles [2]. $\mathrm{GE}$, a $2 \mathrm{D}$ one-atom-thick sheet of $\mathrm{sp}^{2}$-bonded carbon atoms, has been well-known as a promising additive in nanocomposite membranes owing to its remarkable mechanical properties (E 1TPa) and high thermal

\footnotetext{
*Address correspondence to this author at the Faculty of Chemical Engineering, Key Laboratory of Chemical Engineering and Petroleum Processing, Research Institute of Sustainable Energy, Ho Chi Minh City University of Technology, VNU-HCMC, 268 Ly Thuong Kiet Street, District 10 , Ho Chi Minh City, Vietnam; Tel: +84-918498177; Fax: +84 (08) 38651370; E-mail: nhhieubk@hcmut.edu.vn
}

conductivity $\left(3000-5000 \mathrm{Wm}^{-1} \mathrm{~K}^{-1}\right)$ [3]. The presence of GE might restrain the movement of chains in the polymer matrix, reduce swelling, and enhance operating temperature level of membranes. Moreover, the 2D-sheet structure of GE contributes to resist large molecules and so increase in the selectivity. However, the lack of oxygen-containing functional groups on the surface of GE sheet can weaken hydrogen bonds in PVA network as well as disrupt PVA crystallinity [4].

In particular, chemical crosslinking methods have advantages as process simplicity and low energy consumption [5]. Crosslinked structures were obtained from reaction between - $\mathrm{OH}$ groups of PVA chains and $-\mathrm{COOH}$ groups or $-\mathrm{CHO}$ groups of crosslinking agents. The swelling of PVA can be reduced by crosslinking reactions, but the consumption of $-\mathrm{OH}$ groups in PVA chains may decline the hydrophilicity. Therefore, the crosslinker must be able to strengthen network without loss of hydrophilic behaviour of membranes [5]. In a previous study showed that MA crosslinked PVA membranes have reasonable permeation rate and high selectivity compared to the carboxylic acids or aldehyde crosslinked membranes [6].

In this study, the effects of GE filler and MA crosslinker contents on characteristics of nancomposite membranes were investigated. The GE/PVA and MA crosslinked GE/PVA nanocomposite membranes were characterized by X-ray diffraction spectrum (XRD), transmission electron microscope (TEM), Fourier- 
transform infrared spectroscopy (FTIR), and differential scanning calorimetry (DSC), and tensile testing. The PV performance of the MA crosslinked GE/PVA nanocomposite membranes for ethanol dehydration was conducted.

\section{EXPERIMENTAL}

\subsection{Materials}

PVA (Mw = 80000), MA $(99 w t \%)$, sulfuric acid (98wt\%), sodium nitrate (99wt\%), hydrogen peroxide (30wt\%), hydrazine hydrate (35wt\%), and MA (99wt\%) were purchased from Xilong Chemical, China. Graphite (particle size: < $50 \mu \mathrm{m}$, density: $20-30 \mathrm{~g} / 100 \mathrm{~mL}$ ) was purchased from Sigma Aldrich, Germany. Potassium permanganate $(>99.5 \mathrm{wt} \%)$ and ethanol $(96 \mathrm{vol} \%)$ were purchased from ViNaChemsol, Vietnam. All chemicals were used without any further purification.

\subsection{Synthesis of GE}

Graphite oxide ( $\mathrm{GiO}$ ) was synthesized using the modified Hummers' method [7]. According to this method, natural graphite $(2.5 \mathrm{~g})$ was mixed with $\mathrm{NaNO}_{3}$ (1.25g) in $\mathrm{H}_{2} \mathrm{SO}_{4}(98 \%, 60 \mathrm{~mL})$ and kept to be below at $5^{\circ} \mathrm{C}$ (ice bath). After $15 \mathrm{~min}$ stirring, $\mathrm{KMNO}_{4}(7.5 \mathrm{~g}$ ) was slowly added within $30 \mathrm{~min}$ and the temperature of the mixture was controlled under $20^{\circ} \mathrm{C}$. The mixture was then increase heat to $35^{\circ} \mathrm{C}$ and sonicated in $2 \mathrm{~h}$. Then, adding $7.5 \mathrm{~g}$ of $\mathrm{KMnO}_{4}$ and sonicated in $4 \mathrm{~h}$. After that, $400 \mathrm{~mL}$ de-ionized water was added gradually. And then, $30 \%$ hydrogen peroxide was added to reduce the unreacted oxidant until the slurry turned golden yellow. GiO was finally obtained after centrifugation, washing until $\mathrm{pH}=6$, and drying at $60^{\circ} \mathrm{C}$.

$0.1 \mathrm{~g}$ of $\mathrm{GiO}$ was mixed with $100 \mathrm{~mL}$ of deionized water, and $5 \mathrm{~mL}$ of hydrazine solution stirred for a few minutes. Then aqueous dispersions was sonicated for 4h. GE was finally obtained after centrifugation, washing until $\mathrm{pH}=6$, and drying at $60^{\circ} \mathrm{C}$.

\subsection{Membrane Preparation}

\subsubsection{Prepararation of GE/PVA Membranes}

The nanocomposite membranes were fabricated by solution-casting method as follows:

Step 1: $0.65 \mathrm{~g}$ PVA was dissolved in deionized water $(100 \mathrm{~mL})$ at $90^{\circ} \mathrm{C}$.

Step 2: $13 \mathrm{~mL}$ of $\mathrm{GE}$ aqueous suspension $(0.25 \mathrm{mg} / \mathrm{mL})$ corresponding to $0.5 \%$ compared with the weight of dried nanocomposite membranes was dripped into the PVA solution which was then stirred at $90^{\circ} \mathrm{C}$ for $1 \mathrm{~h}$. The suspension was ultrasonicated at $45^{\circ} \mathrm{C}$ for $4 \mathrm{~h}$ to create a homogeneous suspension (GE/PVA).

Step 3: The aqueous suspension was stable at room temperature for $24 \mathrm{~h}$ to form membrane. Then membrane was continued to be dried at $100^{\circ} \mathrm{C}$ for $3 \mathrm{~h}$.

The nanocomposite membranes were named as 0.5GE/PVA, 1.0GE/PVA, 1.5GE/PVA, and 2.0GE/PVA corresponding to GE loadings $0.5 \%, 1.0 \%, 1.5 \%$, and $2.0 \%$, respectively. The effect of GE contents on characteristics of the obtained membranes was investigated by XRD, TEM, FTIR, and DSC.

\subsubsection{Preparation of MA Crosslinked GE/PVA Membranes}

MA and PVA were dissolved in deionized water to make mixtures with different MA percentages of 10,20 , 30 , and $40 \%$ by dry weight. The optimum filler content of GE was blended with the MA/PVA mixtures and stirred in $1 \mathrm{~h}$ at room temperature. Then the suspension was casted and dried to get the nanocomposite membrane. The MA crosslinked GE/PVA nanocomposite membranes were named as GE/PVA-0.1MA, GE/PVA-0.2MA, GE/PVA-0.3MA, and GE/PVA-0.4MA, respectively, with $M A$ contents.

\subsection{Characterization}

XRD patterns were obtained by Advanced X8, Bruker (German) with $\lambda=0.154 \mathrm{~nm}$, step of $4^{\circ} /$ minute from $10^{\circ}$ to $40^{\circ}$.TEM images were taken by JEM-1400 machine with an accelerating voltage of $100 \mathrm{KV}$.FTIR spectra were obtained were obtained in the range of wave number from 4000 to $500 \mathrm{~cm}^{-1}$ during 64 scans on Alpha-E Bruker (Bruker Optik GmbH, Ettlingen, Germany) spectrometer. DSC measurements were performed with DSC-1 (Mettler Tolado, America) differential scanning calorimeter. Tensile testing was performed by AND RTC 1210A (Tensilon, Japan) with the membranes were cut into approximately $5 \mathrm{~mm} x$ $60 \mathrm{~mm}$, and carried out under initial tensile length of $40 \mathrm{~mm}$ and drawing speed of $50 \mathrm{~mm} / \mathrm{min}$.

\subsection{Pervaporation Experiments}

The PV system used in this work is illustrated in Figure 1. The PV dehydration of ethanol was carried out as following: $1 \mathrm{~L}$ of $50 \mathrm{wt} \%$ ethanol feed solution was heated up to $40^{\circ} \mathrm{C}$ and circulated through the 


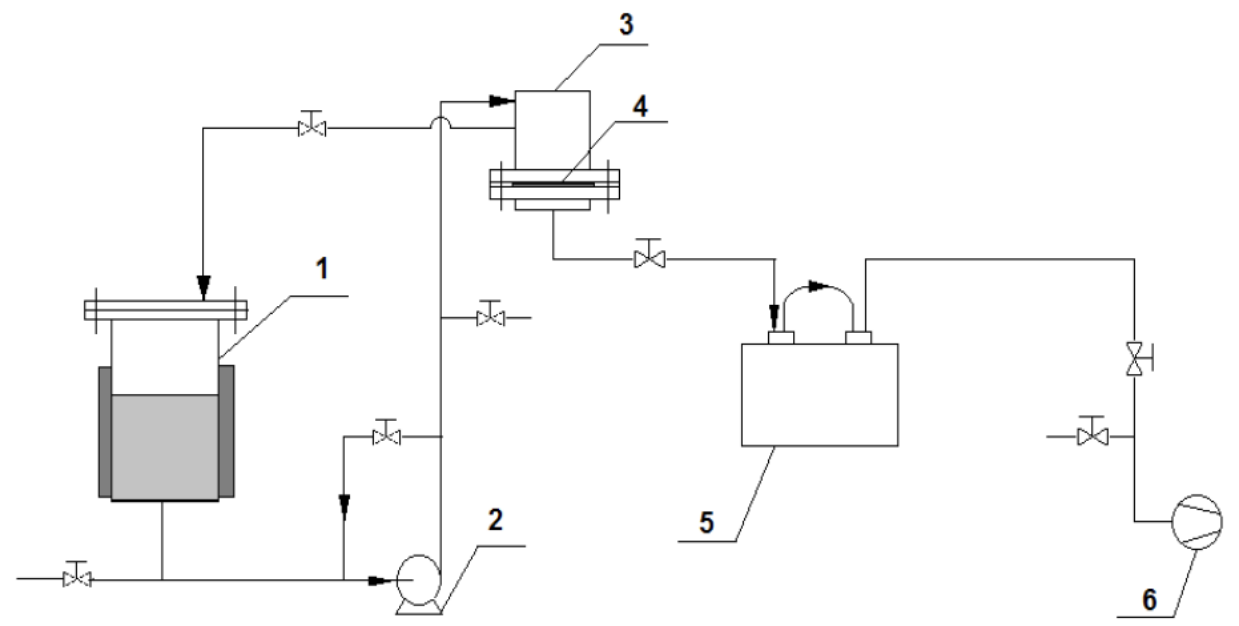

Figure 1: Schematic diagram of PV system.

1. Feed tank. 2. Metering pump. 3. Membrane module. 4. Membrane. 5. Cold trap. 6. Vacuum pump

membrane module from the feed tank. Membrane was placed on a stainless steel screen support in the module with effective membrane area of $28.3 \mathrm{~cm}^{2}$. During the experiments, the pressure at the downstream side was kept at $100 \mathrm{KPa}$ by a vacuum pump. The permeate was condensed in cold trap at $30^{\circ} \mathrm{C}$. For each experiment, the operating time was $2 \mathrm{~h}$ to ensure that a steady state is reached. In addition, each experiment was repeated three times and the results were expressed as average values. The collected permeate in cold trap was weighted to calculate the permeate flux and measured the composition by refractometer to determine the selectivity. The PV membrane performance was expressed in terms of permeate flux $(\mathrm{J})$ and selectivity $(\alpha)$ as follows [8].

$$
J=\frac{1}{A} \frac{\Delta W}{\Delta t} \quad \text { (1) and } \alpha=\frac{y \mathrm{H}_{2} \mathrm{O} / y \mathrm{C}_{2} \mathrm{H}_{5} \mathrm{OH}}{x \mathrm{H}_{2} \mathrm{O} / x \mathrm{C}_{2} \mathrm{H}_{5} \mathrm{OH}}
$$

where $\Delta \mathrm{W}(\mathrm{kg})$ is the weight of permeate during the experimental time $\Delta t(h), A\left(m^{2}\right)$ is the effective membrane area, and $x, y$ are the weight fraction of either water or ethanol in the permeate and the feed, respectively.

\section{RESULTS AND DISCUSSION}

\subsection{Influence of GE Filler Content on the Nanocomposite Membrane Properties}

\subsubsection{XRD Patterns and TEM Image}

XRD patterns of GE and GE/PVA as shown in Figure 2, which indicate that the diffraction peaks of $G E$ at $2 \theta=21 \div 26^{\circ}$ disappeared in the patterns of nanocomposites. All typical diffraction peaks of GE/PVA are located at $2 \theta=19.46 \div 20^{\circ}$, equivalent with that of neat PVA at $2 \theta=19.50^{\circ}$ [9]. In addition, the degree of sharpness and width of the diffraction peaks of GE/PVA and PVA membranes were similarly obtained. This demonstrates the good incorporation of GE in PVA matrix. Furthermore, the appearance of aggregated GE sheets can restrict and order PVA chain arrangement. Therefore, the increased aggregation of GE filler at higher loadings, which leads to decline of crystallinity of GE/PVA membranes [10].

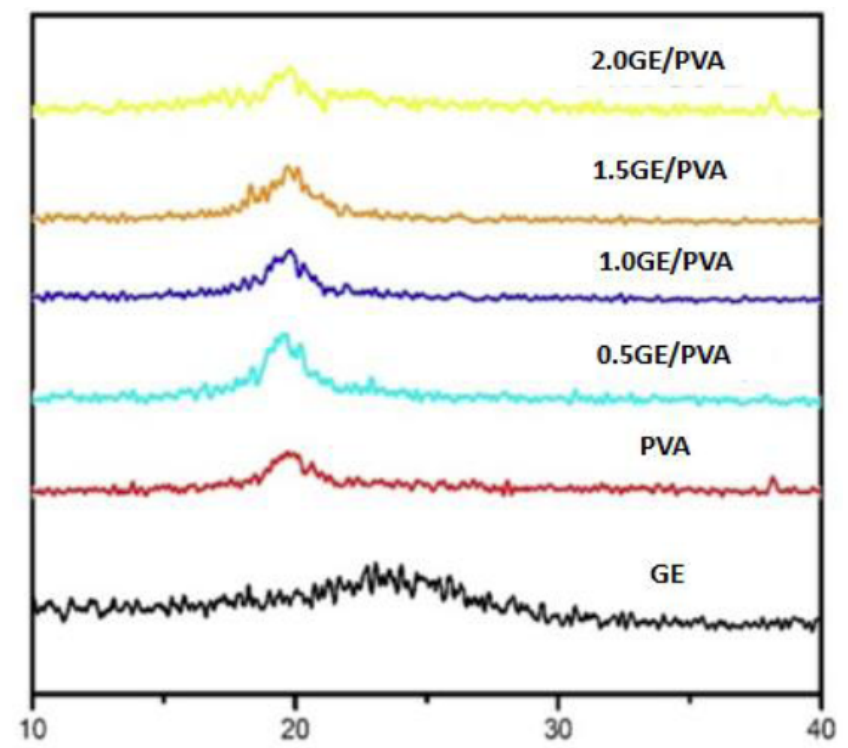

Figure 2: XRD patterns of GE, PVA, and GE/PVA of membranes.

TEM image of 0.5GE/PVA membrane as shown in Figure 3. It shows that the good dispersion of GE in PVA matrix with average thickness of aggregated GE 
sheets is $20 \div 28 \mathrm{~nm}$. This result is in consistence with the incorporation of GE in PVA matrix via the XRD analysis.

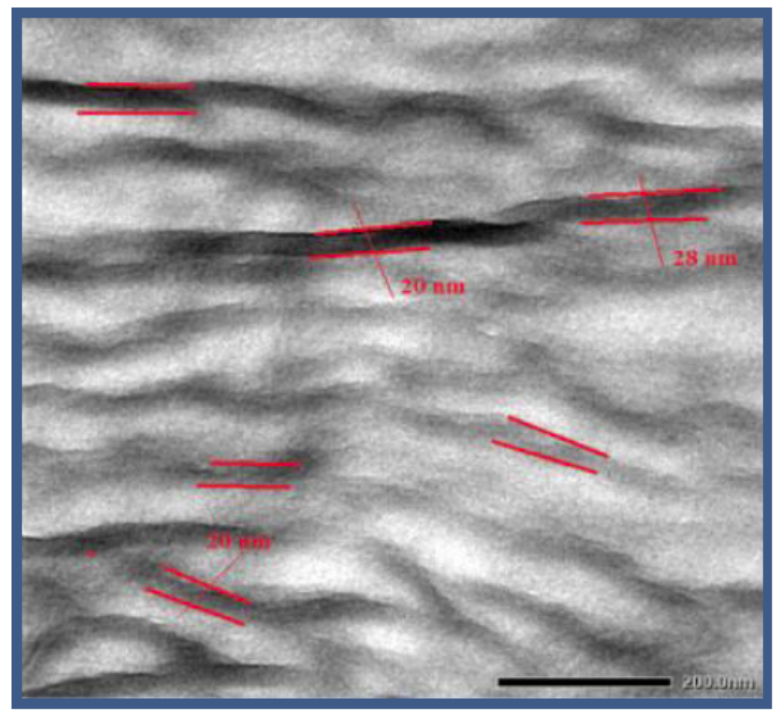

Figure 3: TEM image of membrane.

\subsubsection{FTIR Spectra}

FTIR spectra of GE, PVA, and GE/PVA membranes are shown in Figure 4. Accordingly, in all spectra, the broad and strong peaks at $3200 \div 3500 \mathrm{~cm}^{-1}$ are attributed to the stretching vibration of hydroxyl groups. The strong peak at $2940 \mathrm{~cm}^{-1}$ is assigned to the band of asymmetric $\mathrm{CH}_{2}$ stretching. The two peaks observed at 1712 and $1658 \mathrm{~cm}^{-1}$ are assigned to the stretching vibrational band of $\mathrm{C}=\mathrm{O}$ [11]. The two peaks observed at 1427 and $1330 \mathrm{~cm}^{-1}$ are attributed as $\mathrm{CH}_{3}$ bending vibration and $\mathrm{CH}_{2}$ stretching respectively. The four peaks at $1090,920,850$, and $660 \mathrm{~cm}^{-1}$ are assigned to

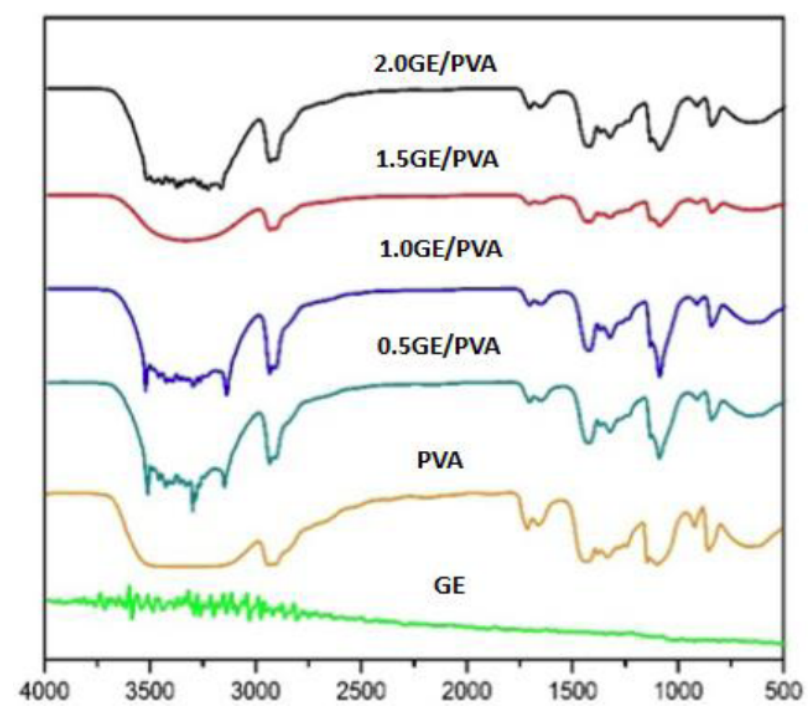

Figure 4: FTIR spectra of GE, PVA, and GE/PVA of membranes. the stretching vibrational band of $\mathrm{C}-\mathrm{O}, \mathrm{CH}_{2}, \mathrm{C}-\mathrm{C}$, and $\mathrm{OH}$ respectively. Comparison of neat PVA and GE/PVA spectra, there are no interactions between GE and PVA matrix in forming nanocomposites. Furthermore, FTIR spectra of GE/PVA membranes show a lot of small peaks in the bands at $3200 \div 3500 \mathrm{~cm}^{-1}$ that can be ascribed to the dissociation of the hydrogen bonds among the hydroxyl groups in PVA chains due to the aggregated GE sheets which cut off hydrogen bonds between PVA chains, resulting in adsorption ability of GE/PVA is not stable [11, 12].

\subsubsection{Thermal Analysis}

The results of DSC are shown in Table 1. Glass transition temperatures- $\mathrm{Tg}$ of nanocomposite membranes are increased with the loading amount of the increasing GE addition. Meanwhile, high mechanical strength of $G E$ contributes to the enhancement of thermal stability of GE/PVA nanocomposites although bonds between GE and PVA are not created $[13,14]$. This result shows the important role of GE in thermal property enhancement of GE/PVA nanocomposite membranes [12].

Table 1: Glass Transition Temperature (Tg) of PVA and GE/PVA Membranes

\begin{tabular}{|c|c|}
\hline Samples & $\mathbf{T g}\left({ }^{\circ} \mathrm{C}\right)$ \\
\hline \hline PVA & 76.34 \\
\hline $0.5 \mathrm{GE} / \mathrm{PVA}$ & 80.27 \\
\hline 1.0GE/PVA & 82.31 \\
\hline 1.5GE/PVA & 83.68 \\
\hline 2.0GE/PVA & 86.70 \\
\hline
\end{tabular}

3.2. Effect of MA Crosslinker Content on the Nanocomposite Membrane Properties

\subsubsection{FTIR Spectra}

FTIR spectra of the crosslinked GE/PVA membranes with different MA contents are shown in Figure 5. The broad band observed from $3200 \div 3500 \mathrm{~cm}^{-1}$ can be assigned to $-\mathrm{OH}$ stretching [4]. As mentioned above, the small vibrations in this band indicated that GE disrupted the hydrogen bonds between the PVA chains. The absorption bands at $1741 \mathrm{~cm}^{-1}$ and $1145 \mathrm{~cm}^{-1}$ may be attributed to $-\mathrm{C}=\mathrm{O}$ and -C-O-Cin ester groups [15]. The appearance of the ester group characteristics and the decrease of the intensity of the $-\mathrm{OH}$ bond in PVA indicated that the esterification reaction between the hydroxyl groups of PVA and the carboxyl groups of MA [16]. However, 
when MA content increases over $20 \%$, the peaks of functional groups appeared with small vibration bands. This indicated that the formation of crosslinking was unstable [4].



Figure 5: FTIR spectra of MA crosslinked GE/PVA of membranes.

\subsubsection{Thermal Analysis}

DSC results are illustrated in Figure 6. It is observed that $\mathrm{Tg}$ increases with increasing MA content in the membranes. Thus, the enhancing crosslinking between the PVA chains showed the improvement in thermal stability of membranes. Specifically, at MA contents less than $30 \%, \mathrm{Tg}$ increased significantly and then remained virtually unchanged with further increase in MA contents. This is due to the formation of crosslinking in the polymer network leading to the restricted thermal movement of polymer chains, and therefore resulting in increased $\mathrm{Tg}$ of the membrane.

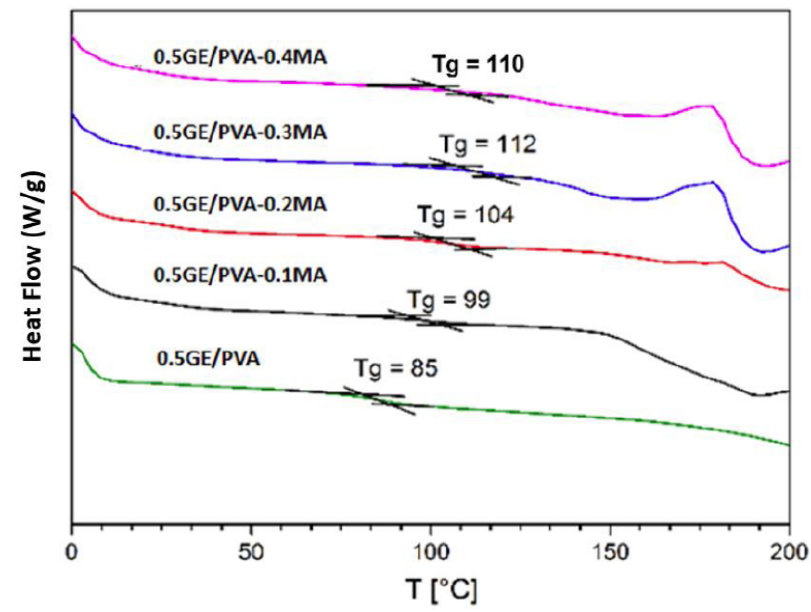

Figure 6: DSC results of MA crosslinked GE/PVA nanocomposite membranes.
Similar results were obtained in the previous studies [17]. Theoretically, one would expect thermal stability to increase with cross-linking because weak Van der Waal's bonds are being replaced by strong covalent bonds. However, at higher contents $(30 \%)$ may cause submicroscopic cracks developing from internal stresses, which result from shrinkage or thermal changes after the mobility of molecular segments has been decreased by crosslinking. Thus, degree of crosslinking reached saturated state and $T_{g}$ nearly unchanged [18].

\subsubsection{Mechanical Properties}

Table 2 presents the tensile strength of membranes with different contents of MA. According to that, the tensile strength of the membranes tended to increase gradually with MA content in the range $0-30 w t \%$ and suddenly decreased with increasing MA up to $40 \mathrm{wt} \%$. The change in mechanical properties of the membranes is attributed to the crosslinking between the PVA chains. The presence of the crosslinking might replace Van der Waals weak bonds and strengthen the polymer network, thereby increasing the tensile strength of membrane [18]. However, exceeding of crosslinking may cause shrinkage and internal stress within the chain networks and those result in a decrease in mechanical properties of membrane [19].

Table 2: Tensile Strength of MA Crosslinked GE/PVA Membranes

\begin{tabular}{|c|c|c|}
\hline Membrane & $\begin{array}{c}\text { Thickness } \\
(\mathbf{m m})\end{array}$ & $\begin{array}{c}\text { Tensile strength } \\
(\mathbf{M P a})\end{array}$ \\
\hline \hline $0.5 \mathrm{GE} / \mathrm{PVA}$ & 0.12 & 49.88 \\
\hline $0.5 \mathrm{GE} / \mathrm{PVA}-0.1 \mathrm{MA}$ & 0.11 & 51.28 \\
\hline $0.5 \mathrm{GE} / \mathrm{PVA}-0.2 \mathrm{MA}$ & 0.10 & 70.95 \\
\hline $0.5 \mathrm{GE} / \mathrm{PVA}-0.3 \mathrm{MA}$ & 0.10 & 71.85 \\
\hline $0.5 \mathrm{GE} / \mathrm{PVA}-0.4 \mathrm{MA}$ & 0.10 & 58.08 \\
\hline
\end{tabular}

\subsection{Effect of MA Crosslinker Content on PV Performance of Membranes}

The result of PV performance of the membranes for dehydration of $50 \mathrm{wt} \%$ ethanol solution is presented in Table 3. It shows that the selectivity increases to a maximum with the MA loading of $20 \mathrm{wt} \%$ and then decreases sharply, whereas, the trend is reversed for the permeate flux. These changes are due to PVA crystallinity is not completely disrupted at lower crosslinking degree $(<20 \%)$ leading to a decrease in permeability [17]. However, the disruption of membrane crystallinity increased significantly at higher 
crosslinking degrees, resulting in enhanced permeability of the membranes [18]. Additionally, the results also proved the role of $\mathrm{GE}$ layers in resisting large molecule through the GE/PVA membrane without MA crosslinking, which slightly reduces permeate flux and increases selectivity compared to the neat PVA membrane. And these results indicated that the MA content of $20 \mathrm{wt} \%$ is suitable for fabricating nanocomposite membrane to dehydrate $50 \mathrm{wt} \%$ ethanol solution by $\mathrm{PV}$ with a permeate flux of $0.690 \mathrm{~kg} / \mathrm{m}^{2} \mathrm{~h}$ and a selectivity of 23.89 at $40^{\circ} \mathrm{C}$.

Table 3: PV Performance of MA Crosslinked GE/PVA Membranes

\begin{tabular}{|c|c|c|}
\hline Membranes & $\begin{array}{c}\text { Permeate flux, } \\
\mathbf{J}\left(\mathbf{k g} / \mathbf{m}^{2} \mathbf{h}\right)\end{array}$ & $\begin{array}{c}\text { Selectivity, } \\
\mathbf{\alpha}\end{array}$ \\
\hline \hline PVA & 1.460 & 5.14 \\
\hline $0.5 \mathrm{GE} / \mathrm{PVA}$ & 1.011 & 9.86 \\
\hline $0.5 \mathrm{GE} / \mathrm{PVA}-0.1 \mathrm{MA}$ & 0.788 & 12.63 \\
\hline $0.5 \mathrm{GE} / \mathrm{PVA}-0.2 \mathrm{MA}$ & 0.690 & 23.89 \\
\hline $0.5 \mathrm{GE} / \mathrm{PVA}-0.3 \mathrm{MA}$ & 0.865 & 10.27 \\
\hline 0.5GE/PVA-0.4MA & 1.110 & 7.89 \\
\hline
\end{tabular}

\section{CONCLUSIONS}

In this study, the effects of GE filler and MA crosslinker contents on the morphological, structural, thermal, and mechanical properties of nanocomposite membranes were investigated. The characterization results indicated that the addition of $0.5 \mathrm{wt} \% \mathrm{GE}$ and $20 w t \% M A$ is suitable for the fabrication of nanocomposite membrane. The 0.5GE/PVA-0.2MA membrane showed a good $\mathrm{PV}$ performance for dehydration of $50 w t \%$ ethanol solution with the total permeation flux is one-half $\left(0.690 \mathrm{~kg} / \mathrm{m}^{2} \mathrm{~h}\right)$ and selectivity is 4 times (23.89) in comparison to those of the neat PVA membrane at $40^{\circ} \mathrm{C}$ and vacuum pressure of $100 \mathrm{KPa}$.

\section{REFERENCES}

[1] Nguyen MT, Dang TTN. Pervaporation as a potential method for fuel ethanol production in VietNam. Proceedings of South East Asian Technical Universities Consortium (SEATUC)-3rd SEATUC Symposium, Johor Bahru - Malaysia, 2009.

[2] Wang N, Ji S, Li J, Zhang R, Zhang G. Poly(vinyl alcohol)graphene oxit nanohybrid pore-filling, membrane for pervaporation of toluene/n-heptane mixtures. J Membr Sci 2013; 455: 113-120. http://dx.doi.org/10.1016/j.memsci.2013.12.023

[3] Novoselov KS, Fal'ko VI, Colombo L, GEllert PR, Schwab MG, Kim K. A roadmap for graphene. Nature 2012; 490: 192-200. http://dx.doi.org/10.1038/nature11458
[4]

Wang J, Wang X, Xu C, Zhanga M, Shang X. Preparation of graphene/poly(vinyl alcohol) nanocomposites with enhanced mechanical properties and water resistance. Polym Int 2011; 60: 816-822.

\section{http://dx.doi.org/10.1002/pi.3025}

[5] Chapman PD, Oliveira T, Livingston AG, Li K. Membranes for the dehydration of solvents by pervaporation. J Membr Sci 2008; 318: 5-37.

http://dx.doi.org/10.1016/j.memsci.2008.02.061

[6] Isiklan N, Sanli O. Separation characteristics of acetic acidwater mixtures by pervaporation using poly(vinyl alcohol) membranes modified with malic acid. Chem Eng Proc 2005; 44: 1019-1027. http://dx.doi.org/10.1016/j.cep.2005.01.005

[7] Hieu NH, Long NHBS. Fabrication and Characterzation of Nanocomposite Nafion-Graphene oxide membranes. J Anal Sci 2013; 18: 47-56.

[8] Wijmans JG, Baker RW. The solution-diffusion model: a review. J Membr Sci 1995; 107: 1-21.

http://dx.doi.org/10.1016/0376-7388(95)00102-I

[9] Kuilla T, Bhadra S, Yao D, Kim NH, Bose S, Lee JH. Recent advances in graphene based polymer composites. Progr Polym Sci 2010; 35: 1350-1375. http://dx.doi.org/10.1016/j.progpolymsci.2010.07.005

[10] Chen J, Huang J, Li J, Zhan X, Chen C. Mass transport study of PVA membranes for the pervaporation separation of water/ethanol mixtures. Desalination 2010; 256: 148-153. http://dx.doi.org/10.1016/j.desal.2010.01.024


characterization of layer-aligned poly(vinyalcohol)/graphenen anocomposites. Polymer 2010; 51: 3431-3435. http://dx.doi.org/10.1016/j.polymer.2010.05.034

[12] Baker RW. Membrane technology and applications. John Wiley \& Sons Ltd.

[13] Dhand V, Rhee KY, Kim HJ, Jung DH. A Comprehensive Review of graphene Nanocomposite: Research Status and Trends. J Nanomater 2013.

http://dx.doi.org/10.1155/2013/763953

[14] Bao C, Guo Y, Song L and Hu Y. Poly(vinyl alcohol) nanocomposite based on graphene and graphite oxide: a comparative investigation of property and mechanism. J Mater Chem 2013.

[15] Li C, Vongsvivut J, She X, Li Y, She F, Kong L. New insight into non-isothermal crystallization of PVA-graphene composites. Phys Chem Chem Phys 2014; 16: 22145-22158. http://dx.doi.org/10.1039/C4CP03613A

[16] Guan H-M, Chung T-S, Huang Z, Chng ML, Kulprathipanja S. Poly(vinyl alcohol) multilayer mixed matrix membranes for the dehydration of ethanol-water mixture. J Membr Sci 2006; 268: 113-122. http://dx.doi.org/10.1016/j.memsci.2005.05.032

[17] Peng F, Jiang Z, Hoek EMV. Tuning the molecular structure separation performance and interfacial properties of poly(vinyl alcohol)-polysulfone interfacial composite membranes. J Membr Sci 2011; 368: 26-33. http://dx.doi.org/10.1016/j.memsci.2010.10.056

[18] Nielsen LE. Cross-Linking Effect on Physical Properties of Polymers. J Macromol Sci Part C: Polymer Rev 1969; 3: 69103. http://dx.doi.org/10.1080/15583726908545897

[19] Gohil JM, Bhattacharya A, Ray P. Studies on the Crosslinking of Poly(vinyl alcohol). J Polymer Res 2013; 13: 161169.

http://dx.doi.org/10.1007/s10965-005-9023-9 